\title{
Tensile Strength of Carbon Fiber/Epoxy Composite Manufactured by the Bladder Compression Molding Method at Variable Curing Temperatures
}

\author{
${ }^{1}$ A. D. Setyoko \\ ${ }^{2} \mathrm{G}$. Nugroho
}

${ }^{1}$ Master's Degree in Mechanical Engineering, Department of Mechanical and Industrial Engineering, Universitas Gadjah Mada Jl. Grafika 2, Yogyakarta 55281, Indonesia

${ }^{2}$ Manufacturing Engineering, Politeknik ATMI Surakarta, Jl. Adisucipto/Jl. Mojo no. 1, Karangasem, Laweyan, Surakarta, 57145, Tlp. 0271714466

Email: 1dwi.setyoko@atmi.ac.id

\section{Keywords}

bladder compression molding, mechanical property, carbon fiberepoxy composite.

\begin{abstract}
Corrosion-resistant, high-strength, low-density composite materials are seeing increased applications in a wide variety of products. The composite constituents of matrix and reinforcement require molding technologies and methods to generate products. The bladder compression molding method is an effective method of manufacturing of composite products with a tubular shape, cavity, and/or closed contour. The properties of the composite materials produced are determined by three variables, namely curing pressure, temperature, and time. This research was conducted to learn the effect of temperature on the mechanical properties of the composite materials produced from the process with the bladder compression molding method. Based on the thickness, tensile strength, and modulus of elasticity of the product from the experiment conducted, the optimal temperature of the process was found to be $120{ }^{\circ} \mathrm{C}$.
\end{abstract}




\section{Introduction}

Use and utilization of composite materials have recently been increasingly widespread and developing. Composite materials start to find applications as product components in place of other materials. This increasingly prevalent composite use is due to the advantages the composite carries, including corrosion resistance, strength, and low density (Anderson \& Altan, 2014). The growing use and utilization of these composite materials also have an impact on the development of manufacturing technologies in the making of products from composites.

A composite is a mixture of two separate materials or more that can be composed of metal, ceramic, and polymer materials. A composite is able to bring up the properties not expressed by the individual constituents and at the same time join together the best properties of each of the materials (Callister \& Rethwisch, 2014). A composite is made up by matrix and reinforcement. The basic constituents of the composite come with distinct basic properties which are combined to produce a single material with better properties. The bringing up of the superior properties desired is highly dependent on the technologies applied in the composite manufacturing process. One of the technologies that can be applied in a manufacturing process is the bladder compression molding.

The bladder compression molding is an effective method of composite manufacturing as it has the capability of forming the outer surface through a negative mold and the inner surface with application of bladder (balloon) pressure. This specific method is highly useful for production of items with a tubular, hollowed, or other closed-contour form (Anderson and Altan, 2012). Using mold, this method comes as extremely handy in the mass production of small- to medium-sized components of complex geometries (Anderson, 2014). The use of a mold also minimizes secondary cutting operations. In the bladder compression molding method, the combining of the materials is performed using top and bottom parts of a mold and a bladder (balloon). The upper and lower mold parts have the negative form of the product, while the bladder the positive, following the shape of the product to be manufactured. The bladder functions as a suppressor of the materials to be mixed. With this application of pressure, the constituents can properly be combined together and shaped after the mold over a curing process. Other than pressuring, heating at a given temperature and over a given period is also performed during the curing process. The properties of the composite materials produced are highly dependent on the three variables above: the pressure, temperature, and time applied during the curing process.

To obtain optimal mechanical properties and characteristics from an epoxy composite, the composite must be subjected to a curing cycle from which epoxy density with a high cross-link level is generated (Gibson, 2012). This curing cycle involves a combination of curing temperature and time. Higher curing temperatures produce more refined reactions with higher cross-linking levels than do lower temperatures. For optimal cross-linking density, a curing process at a fairly high temperature will produce sufficient kinetic energy for a more even chemical reaction. Generation of a high crosslinking density will enable the composite previously subjected to a curing process to exhibit the best mechanical and physical properties. On the other hand, the application of a sub-optimal curing temperature will cause the epoxy to undergo an excessively fast curing process. This excessively fast curing process will lead to the formation of residual stress which will harm the mechanical properties and characteristics of the composite produced. Curing temperatures that reach the glass-transition temperature ( $\mathrm{Tg}$ ) will subject the composites to degradation of properties related to stiffness, heat capacity, and thermal expansion (Callister \& Rethwisch, 2014). Thus, all composite formation methods, including bladder 
compression molding method, require a close attention in the determination of the curing parameters, especially temperature.

The objectives of this research were 1) to develop a system and equipment of composite manufacturing by the bladder compression molding method, 2) to analyze the effect of curing temperature on tensile strength in composites of epoxy matrix and reinforcing carbon fabric manufactured by the bladder compression molding method, 3) to analyze the effect of curing temperature through tensile testing in composites of epoxy matrix and reinforcing carbon fabric manufactured by the bladder compression molding method, and 4) to obtain data of optimal curing temperature in the manufacturing of composites of epoxy matrix and reinforcing carbon fabric by the bladder compression molding method.

\section{Methodology}

This research stressed the composite formation process with the bladder compression molding method.

This method was applied with a mold that had a rectangular mold hollow $235 \mathrm{~mm}$ long, $180 \mathrm{~mm}$ wide, and $20 \mathrm{~mm}$ thick. Every corner of the lengths and widths of the mold hollow had a $10-\mathrm{mm}$ radius and the corner of the thickness a $6-\mathrm{mm}$ radius. The mold had two parts: the upper and the lower ones. Every mold part was equipped with a heater and a thermo control used for adjusting the curing temperature.

To obtain the composite form and density of interest, a bladder was used as a mold core. The bladder was made from silicon rubber approximately $5 \mathrm{~mm}$ thick. A piece of sheet was shaped following the shape of the mold hollow on the lower mold part. Each part had a mold cavity and heating cavity on the rear side. The heating cavity was smaller in size.

In this research, the pressure of the bladder was maintained at 5 bar over the composite resin curing process.
The process stages involved in this research can be described in the chart in Figure 1.

Mold manufacturing started from the designing, material ordering, and machining. The mold manufactured consisted two upper parts and covers. The mold used for making the composite specimen in this research was made from aluminum. The dimensions of the mold on the outside were $322 \mathrm{~mm}$ in length, $240 \mathrm{~mm}$ in width, and $40 \mathrm{~mm}$ in thickness. Meanwhile, the cavity of the mold was 262 $\mathrm{mm}$ long, $180 \mathrm{~mm}$ wide, and $20 \mathrm{~mm}$ thick. The sketch of the mold dimensions can be seen in Figure 2.

The bladder was made from silicon rubber. Silicon rubber was cast into a bladder in the mold. As with the mold for forming the specimen, the bladder mold also consisted of two main parts: upper part and lower part, each of which also came with a cavity.

Bladder forming was performed in the following steps: 1) prepare the mold (upper and lower) in an open state, 2) smear oil or release gel on the surface of the cavity thinly and evenly, 3) apply silicon rubber or latex rubber on the cavity of both mold parts and wait for some time, 4) close the two mold parts together after the silicon rubber or latex rubber was considered to start thickening but was still glueable, and 5) after the material was estimated to have hardened, the mold was opened and the bladder was removed from the cavity.

After the mold, bladder, heater, and control system were assembled, composite forming with the bladder compression molding method could be performed.

The composite product was formed by first applying release gel on the mold, then applying reinforcing fiber and resin alternately to form composite layers, placing a bladder between the upper and lower mold parts and then closing them together, applying pressure on the bladder, and adjusting the heat through the thermo control.

After 90 minutes, the composite product forming process was ended. 


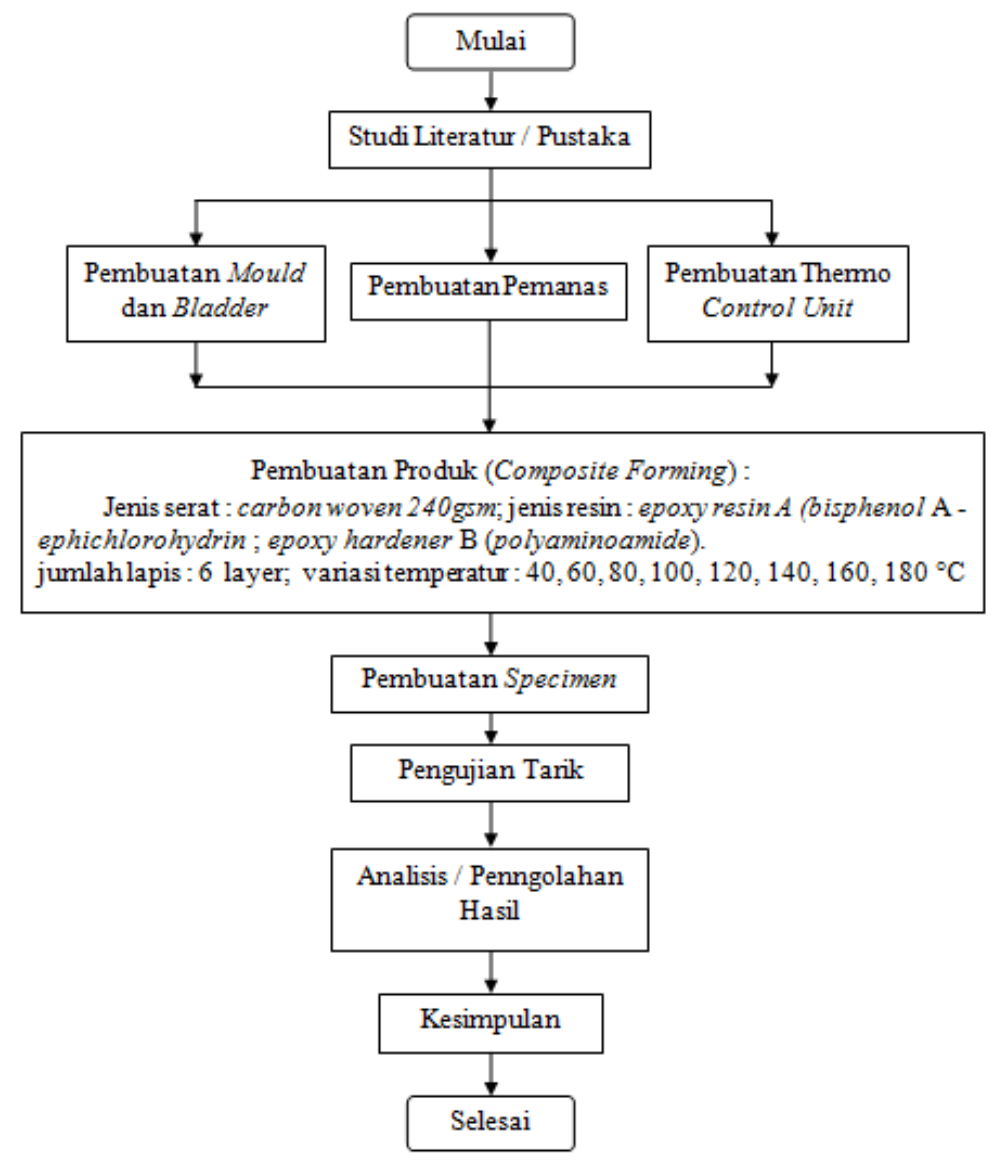

Figure 1. Research Flow Chart
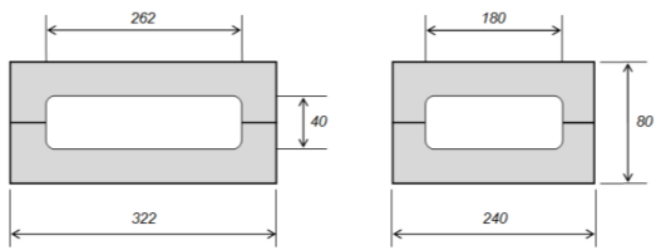

Figure 2. Composite Mold Dimensions

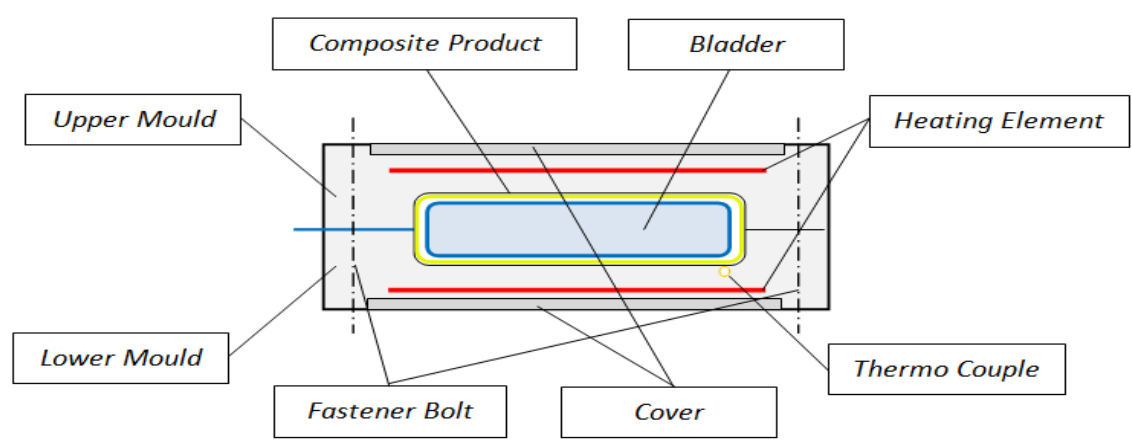

Figure 3. Bladder Compression Molding Unit Sketch 
The equipment used for the composite product forming consisted of 1) a mold set equipped with a heater and a thermo control, 2) a temperature control unit, 3) a bladder core with nipple compressor, 4) regulator valve, and 5) pneumatic hose.

Meanwhile, the materials used were 1) reinforcement from $240 \mathrm{gsm}$ of carbon clothe woven (fabrics) and 2) a matrix from epoxy resin A (bisphenol A-epichlorohydrin) and epoxy harderner B (polyaminoamide).

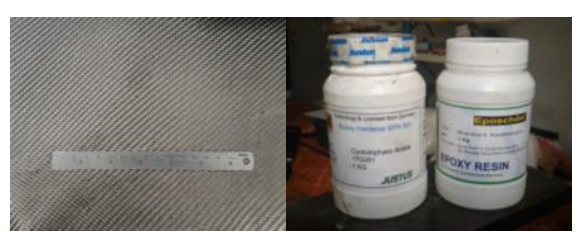

Figure 4. Composite Materials

The materials used in forming the composite product with the bladder compression molding method are shown in Figure 4.

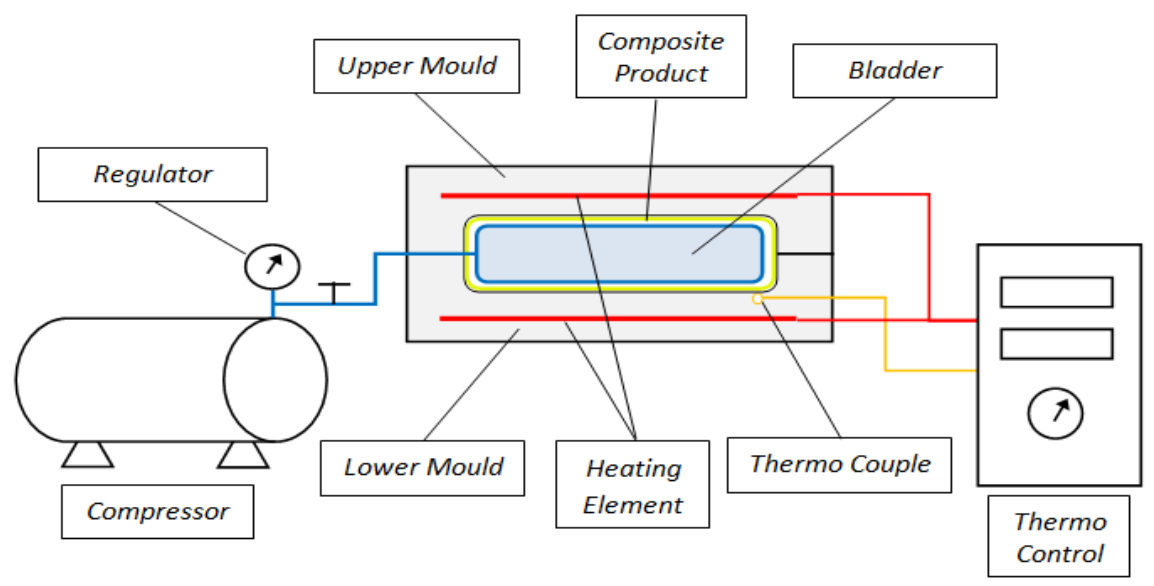

Figure 5. Composite Formation with the Bladder Compression Molding Method

The scheme of the composite formation process with the bladder compression molding method is shown in Figure 5, and the implementation in Figure 6.

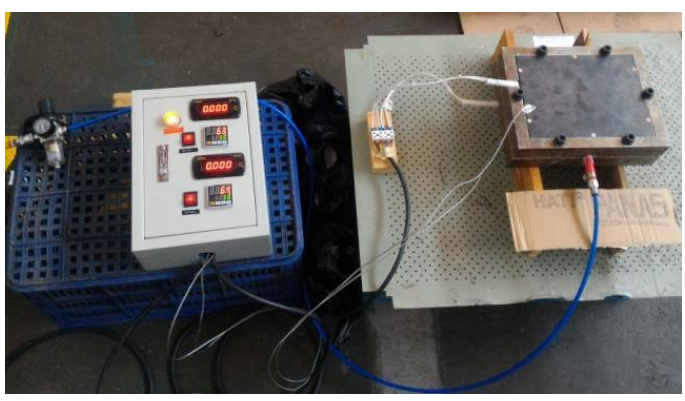

Figure 6. Implementation of Composite Forming with the Bladder Compression Molding Method

The steps of the composite making can be outlined as follows: 1) smear release gel on the cavity surface thinly and evenly; 2) apply fiber and $\mathrm{n}$ on the mold and bladder in six layers; 3) place all of the materials prepared previously into the bladder mold, then close the mold with bolts fastened; 4) inflate the bladder until a pressure of 5 bar is reached; 5) heat the heater until the mold reaches a curing temperature and keep the temperature for 90 minutes; 6) cease the heating and start cooling; and 7) lower the bladder pressure until zero and remove the specimen from the mold.

The composite produced from this process with the bladder compression molding method was then tested for its mechanical properties. This test was useful to figure out the quality of the product. 

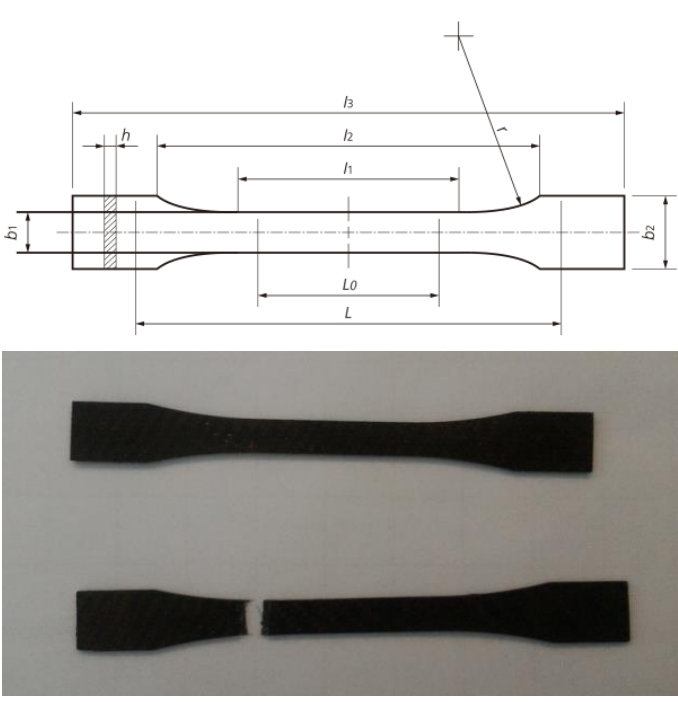

Figure 7. ASTM D638 Tensile Test Object

The mechanical properties were identified through a tensile test. Thus, this product was then cut using a router machine in a shape meeting the ASTM D638 tensile test standard with the observed part being b1 $=12.4 \mathrm{~mm}$ in width and Lo $=50 \mathrm{~mm}$ in length (ASM Handbook, 2000). The tensile test object and the testing process are shown in Figures 7 and 8.

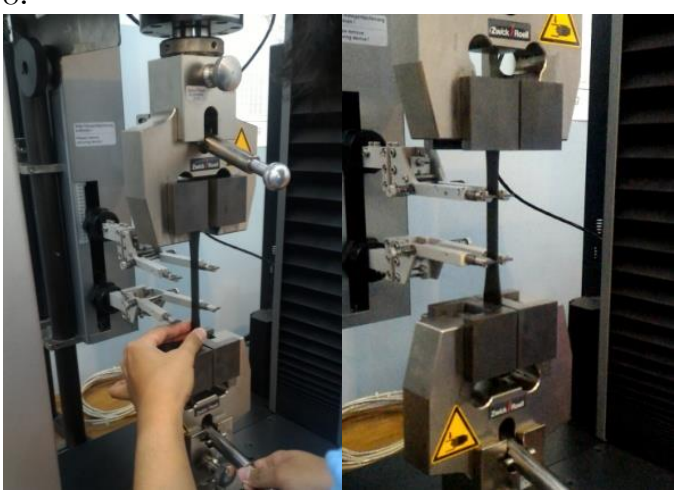

Figure 8. Fixing and tensile testing of the composite product with the ASTM D638 method in the test machine

\section{Results and Discussion}

From the observation conducted during the product manufacturing process with the bladder compression molding method, it was found that temperature affected the curing process speed and the liquidity of resin before the curing process.
The speed and the amount of cross-linking affected the bond structure formed in the resin and the carbon fiber as reinforcement. This impact can be seen in the product strength as obtained from the tensile testing.

From the tensile testing, some data were obtained as presented in Table 1. The data demonstrate how temperature affected the dimensions and the properties of the composite product manufactured with the bladder compression molding method.

The effect of curing temperature on the product geometries can be observed from the product thickness resulted (Figure 9).

The test object thickness tended to decrease when the temperature was increased from $40{ }^{\circ} \mathrm{C}$, and a minimum thickness was reached when the temperature was at $120^{\circ} \mathrm{C}$. Past $120^{\circ} \mathrm{C}$, the object tended to increase in thickness. The product thickness for each process temperature parameter is shown in Figure 9.

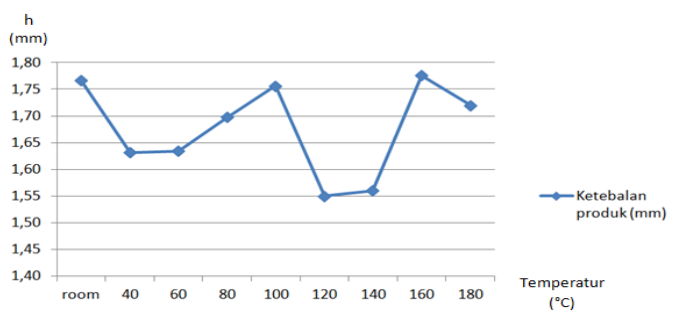

Figure 9. Chart of the Relationship between Product Thickness (h) and Curing Temperature 
Table 1. Tensile Test Result Data

\begin{tabular}{|c|c|c|c|c|c|c|c|c|}
\hline \multirow{2}{*}{ No } & Temp & Force & Et & $\sigma \mathrm{M}$ & $\sigma \mathrm{B}$ & $\mathrm{h}$ & $\mathrm{b}$ & $\mathrm{A}_{0}$ \\
\cline { 2 - 9 } & ${ }^{\circ} \mathrm{C}$ & $\mathrm{N}$ & $\mathrm{MPa}$ & $\mathrm{MPa}$ & $\mathrm{MPa}$ & $\mathrm{mm}$ & $\mathrm{mm}$ & $\mathrm{mm}^{2}$ \\
\hline 1 & $\mathrm{room}$ & 10950,81 & 41060 & 493 & 493 & 1,77 & 12,59 & 22,24 \\
\hline 2 & 40 & 11301,85 & 48900 & 557 & 557 & 1,63 & 12,46 & 20,33 \\
\hline 3 & 60 & 9357,46 & 41780 & 465 & 465 & 1,63 & 12,35 & 20,17 \\
\hline 4 & 80 & 9562,92 & 40600 & 453 & 453 & 1,70 & 12,49 & 21,20 \\
\hline 5 & 100 & 10124,33 & 39340 & 455 & 455 & 1,76 & 12,67 & 22,24 \\
\hline 6 & 120 & 11510,94 & 49920 & 591 & 591 & 1,55 & 12,56 & 19,47 \\
\hline 7 & 140 & 10632,98 & 43800 & 544 & 544 & 1,56 & 12,56 & 19,60 \\
\hline 8 & 160 & 10978,92 & 41280 & 499 & 499 & 1,78 & 12,52 & 22,21 \\
\hline 9 & 180 & 11215,76 & 49560 & 523 & 523 & 1,72 & 12,47 & 21,45 \\
\hline
\end{tabular}

The test object thickness tended to decrease when the temperature was increased from $40{ }^{\circ} \mathrm{C}$, and a minimum thickness was reached when the temperature was at $120^{\circ} \mathrm{C}$. Past $120^{\circ} \mathrm{C}$, the object tended to increase in thickness. This was attributed to the change in the liquidity at every process temperature and the resin hardening speed over the curing process. At constant pressure of 5 bar, more liquid resin would flow absorbed into the reinforcing fiber. It was also easier for the excess resin volume to break out from the product and mold through the breather and gaps at the mold periphery. The product's thickness rebounded at $160^{\circ} \mathrm{C}$ because curing processes speed up at high temperatures.

The effect of curing temperature on the product's tensile strength is shown in Figure 10. This figure shows that tensile strength was inclined to drop at temperatures between 60 ${ }^{\circ} \mathrm{C}$ and $80{ }^{\circ} \mathrm{C}$ then bounce back at $100{ }^{\circ} \mathrm{C}$ to $120^{\circ} \mathrm{C}$. At temperatures $140{ }^{\circ} \mathrm{C}$ and $160{ }^{\circ} \mathrm{C}$, the tensile strength fell again.

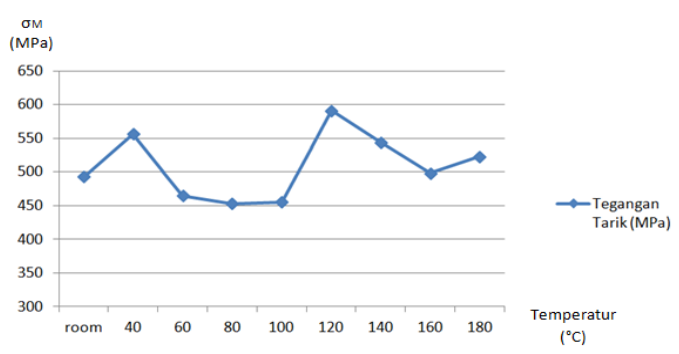

Figure 10. Chart of the Relationship between Tensile Strength $(\sigma \mathrm{M})$ and Curing Temperature
The increase in the product's tensile strength was resulted from the strengthening bond between resin and fiber where resin became more liquid at high temperatures and from the product's thinner dimension. With the same fiber volume and thinner product dimension, it can be concluded that the fiber's volume fraction was higher.

Figure 11 shows the effect of curing temperature on the modulus of elasticity of the product that was manufactured with the bladder compression molding method. The trend was identical with that of the tensile strength changes.

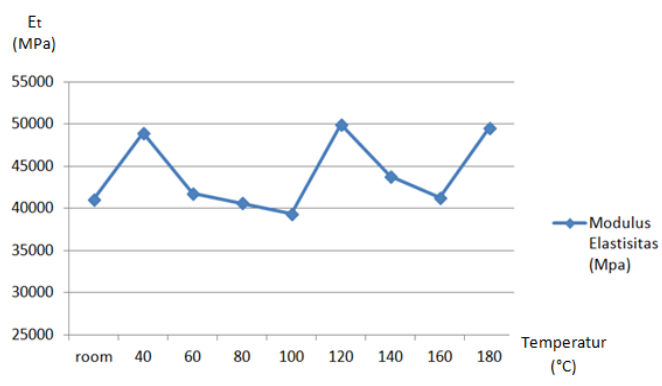

Figure 11. Chart of the Relationship between Modulus of Elasticity of the Product and Curing Temperature 


\section{Conclusion}

In the composite manufacturing with the bladder compression molding method, temperature played a pivotal role influencing the product's quality.

1. Temperature had effects on the product's thickness, tensile strength, and modulus of elasticity.

2. The composite produced by the bladder compression molding had the lowest thickness at the curing temperature 120 ${ }^{\circ} \mathrm{C}$.

3. The tensile strength and modulus of elasticity of the composite produced by the bladder compression molding reached a maximum at the temperature $120^{\circ} \mathrm{C}$

4. From the data outlining and analysis, it is concluded that the optimal curing temperature for the composite forming by the bladder compression molding is $120^{\circ} \mathrm{C}$.

\section{References}

Anderson, J., \& Altan, M. (2012). Properties of Composite Cylinders Fabricated by Bladder Assisted Composite Manufacturing . Journal of Engineering Materials and Technology 134, 1-7.

Anderson, J., \& Altan, M. C. (2014). Bladder Assisted Composite Manufacturing (BACM): Challenges and Opportunities. Polymer Processing Society EuropeAfrica Conference (hal. DOI10.13140/2.1.2139.6169). Tel Aviv: ResearchGate.

Anderson, J., Kelly, A., \& Altan, M. (2013). Fabrication of Composite Laminates by VacuumAssisted Resin Transfer Molding Augmented with an Inflatable Bladder. Researchgate, 2-13.

Askeland, D. R., Fulay, P. P., \& Wright, W. J. (2010). The Science and Engineering of Materials, Sixth Edition. Stamford, CT 06902: Cengage Learning.

ASM Handbook. (2000). Mechanical Testing and Evaluation, ASM Handbook Vol. 8. Materials Park, OH 44073-0002: ASM International.
Callister, W. D., \& Rethwisch, D. G. (2014). Materials Science and Engineering. New Jersey: John Willey \& Sons, Inc.

Gibson, R. F. (2012). Principles of Composite Material Mechanics. Boca Raton, London, New York: CRC Press.

J. P. Anderson, M. C. (2014). Composite laminates fabricated by bladder assisted composite manufacturing (bacm): 